\title{
Bertrand Competition Can Yield Higher Prices than Monopoly
}

\author{
Helge Sanner*
}

February 15, 2005

\begin{abstract}
If we take into account the spatial dimension of markets, prices of incumbent firms may be higher, and consumer surplus may be lower with competition. This result obtains unambiguously, in the supposedly highly competitive case of Bertrand competition. Moreover, we are able to show that consumer welfare may be reduced by competition, if the distance between the firms' sites is sufficiently large.
\end{abstract}

Keywords: Spatial competition vs. monopoly; Consumer welfare JEL-codes: D42; L11; R32

Paper competes to the Young Economists Award

${ }^{*}$ Correspondence to: Helge Sanner, University of Potsdam, Department of Economics and Social Sciences, August-Bebel-Straße 89, 14482 Potsdam, Germany. Email: sanner@rz.uni-potsdam.de. Tel: $+49.331 .977-4636$ 


\section{Introduction}

We usually suppose that market entry is beneficial for consumers and harmful for incumbent firms, because intensified competition brings about lower prices. Yet, this may not always be true if the spatial dimension of markets is taken into account - even in the highly competitive case of Bertrand competition when firms are able to compete in prices. Perloff, Suslow and Seguin (1996) is concerned with the possibility of price increases due to market entry in a competitive framework à la Bertrand. This note aims at generalizing and extending their results in several regards. In particular, we allow for the possibility that the amount purchased differs among consumers, and, by defining an appropriate measure, we are able to show that consumers may fare better with monopoly, even though average transport costs are higher.

\section{The setting}

Our basic model draws on Beckmann (1968). Assume a linear market. Homogeneous, rent-maximizing consumers are distributed evenly at density one. Each consumer is characterized by the same individual demand function:

$$
q(r)= \begin{cases}a-b p(r) & \forall p(r) \leq a / b \\ 0 & \forall p(r)>a / b\end{cases}
$$

where $q$ denotes the quantity of a homogenous commodity, and $a / b$ is the prohibitive price. $p(r)$ denotes the price of the commodity at a location $r$ units away from the firm's site, $p(r)=m+r t$, where $m$ and $t$ stand for the mill or f.o.b. price, and transport costs per unit distance. A profit-maximizing firm (the incumbent) faces a fixed market boundary in distance $R_{f}$ at one side, which may or may not be binding. Such fixed boundary may be due to geographic specialties like a river or collusion with a neighboring firm. Until the entry of a competitor, the firm serves the market at each side until $R_{f}$ or the distance $R_{M}$ where demand falls to zero:

$$
R_{M}=\frac{a-b m_{M}}{b t}
$$

The index $M$ stands for 'monopolist'. If constant marginal costs are denoted by $c$, and no fixed costs occur, profits $\pi$ are

$$
\pi_{M}=\left(m_{M}-c\right)\left[\int_{0}^{R_{M}}\left(a-b m_{M}-b r t\right) d r+\int_{0}^{R_{f}}\left(a-b m_{M}-b r t\right) d r\right]
$$


From the first-order condition the monopoly mill price obtains:

$$
\begin{aligned}
& m_{M}=\frac{1}{3 b}\left(2 a+2 b R_{f} t+c b-\alpha\right) \\
& \text { with } \quad \alpha=\sqrt{\left(a-b c-b R_{f} t\right) \cdot\left(3 b R_{f} t+a-b c\right)+10 b^{2} R_{f}^{2} t^{2}}>0
\end{aligned}
$$

Inserting $m_{M}$ in (2), setting $R_{f}=R_{M}$ and solving for $R_{M}$ obtains

$$
\bar{R}=\frac{2(a-b c)}{3 b t}
$$

$\bar{R}$ is the range of the monopolistic market area at both sides if boundary $R_{f}$ is nonbinding. In this case the monopolistic mill price becomes

$$
m_{M}(\bar{R})=\frac{a+2 b c}{3 b}
$$

If a competitor enters at distance $S<2 R_{M}$ from the incumbent, the boundary between their market shares $\left(R_{b}\right)$ is where prices are equal: $m_{i}+R_{b} t=m_{j}+\left(S-R_{b}\right) t$, where $m_{i}$ and $m_{j}$ denote the incumbent's and the newcomer's mill price, respectively, and $R_{b}$ is the distance of the boundary from the incumbent's site. It yields as

$$
R_{b}=\frac{m_{j}-m_{i}+t S}{2 t}
$$

Each competitor supplies half of the market area between them if prices are equal $\left(m_{i}=m_{j}\right.$, see Puu $(2001$, p. 3$\left.)\right)$.

\section{The scope for higher prices}

In this section, we derive the conditions under which the incumbent firm's mill price rises due to competition. We assume that one symmetric newcomer enters such that the incumbent is located between the newcomer and $R_{f}$.

$$
\pi_{i}=\left(m_{i}-c\right)\left[\int_{0}^{R_{b}}\left(a-b m_{i}-b r t\right) d r+\int_{0}^{R_{f}}\left(a-b m_{i}-b r t\right) d r\right]
$$

Maximizing (8) gives

$$
\begin{aligned}
& \quad m_{i}=\frac{1}{4 b}\left(2 a+2 c b+3 b t S+8 b R_{f} t-\beta\right) \\
& \text { with } \quad \beta=\sqrt{4(a-b c) \cdot(a-b t S-b c)+b^{2} t^{2} \cdot\left(13 S^{2}+48 R_{f} S+80 R_{f}^{2}\right)}>0
\end{aligned}
$$

A second solution does not fulfill the second-order condition. 


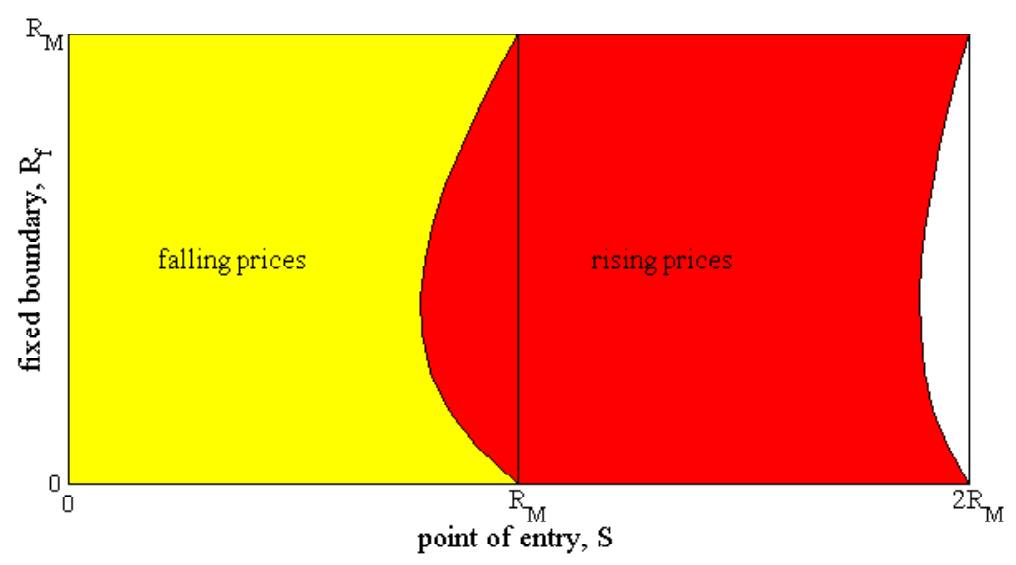

Fig. 1: The scope for rising prices $(a=b=t=1, c=0.1)$

Setting equal (4) and (9) and solving for $S$ yields two distances between the firms at which the incumbent fetches the same price with or without market entry:

$$
\begin{aligned}
S^{\prime} & =\frac{-2}{3 b t}\left(a-c b+4 b R_{f} t-2 \alpha\right) \\
S^{\prime \prime} & =\frac{2}{3 b t}\left(a-c b-2 b R_{f} t+\alpha\right)=2 R_{M}
\end{aligned}
$$

The following proposition states how entry impacts on the incumbent firm's price, depending on the distance of the newcomer.

\section{Proposition 1}

At distances $S=S^{\prime} \leq R_{M}$ and $S \geq S^{\prime \prime}=2 R_{M}$ between the incumbent's and the newcomers site the incumbent's mill price remains constant. At all distances $S \in\left[0, S^{\prime}\right)$ it decreases due to market entry (if we assume away space, $S=0$, the usual result comes up), and at all distances $S \in\left(S^{\prime}, S^{\prime \prime}\right)$ it increases (see Fig. 1).

A sketch of the proof follows: At distances $S \geq S^{\prime \prime}=2 R_{M}$ each firm is a local monopoly. Therefore, the price of the incumbent is the monopoly price $\left(m_{i}=m_{M}\right)$. The first two derivatives of $m_{i}$ with respect to $S$ are

$$
\begin{gathered}
\frac{d m_{i}}{d S}=\frac{t}{4 \beta}\left(3 \beta-2 c b-13 b t S-24 b R_{f} t+2 a\right) \\
\frac{d^{2} m_{i}}{d S^{2}}=\frac{-4 t^{2} b}{\beta^{3}}\left[29 b^{2} t^{2} R_{f}^{2}+(3 a-3 c b)\left(a-c b+2 b R_{f} t\right)\right]<0
\end{gathered}
$$


Since $m_{M}$ is independent from $S$, and $d^{2} m_{i} / d S^{2}<0$, it follows that $m_{i}$ exceeds $m_{M}$, and there is a single maximum, between $S^{\prime}$ and $S^{\prime \prime} . R_{M}=S^{\prime}$ for $R_{f} \in\{0, \bar{R}\}$. Since

$$
\frac{d^{2}\left(R_{M}-S^{\prime}\right)}{d R_{f}^{2}}=\frac{-6 b t(a-c b)^{2}}{\alpha^{3}}<0
$$

it follows that $S^{\prime}<R_{M} \forall R_{f} \in(0, \bar{R})$. This means that the incumbent's mill price rises due to entry of a competitor for more than half of the values $S \in\left[\begin{array}{ll}0,2 & R_{M}\end{array}\right]$ if $R_{f} \in(0, \bar{R})$ (see Fig. 1). Entry causes an increase of the incumbent's price if the newcomer locates outside or close to the boundary of the former monopoly market. If $R_{f} \in\{0, \bar{R}\}$ entry causes a higher mill price if the newcomer locates outside the former monopoly market.

With the assumed individual demand function the further away a consumer is from the firm, the more elastic is his demand. Entry has two opponent effects on the

price. On the one hand, the optimum price is lower because higher prices lead to a loss of market share. On the other hand, the remaining consumers' demand is relatively inelastic in average, which works towards a higher price. The latter effect prevails if the entry point is beyond $S^{\prime}$ and vice versa. At point $S^{\prime}$ both effects are equally strong.

\section{When do consumers fare better with monopoly?}

Consumers are better off with monopoly if the lower mill price outweighs the disadvantage of higher average transport costs. If the newcomer locates in distance $S^{\prime}$, total consumer surplus increases due to competition because the mill price of the incumbent remains stable (see proposition 1 ), and all consumers located in the interval $\left(S^{\prime} / 2, R_{M}\right.$ ] save transport costs. To decide whether consumers that have been supplied by a monopolist fare better with competition or not, we must neglect the effect of a larger number of consumers. Therefore, we calculate total consumer surplus within the area that once belonged to the monopoly market $\left(\Psi_{C}\right)$ :

$$
\begin{aligned}
\Psi_{C}=\frac{1}{2 b} & \left\{\int_{0}^{R_{f}}\left(a-b m_{i}-b r t\right)^{2} d r\right. \\
& \left.+\int_{0}^{R_{b}}\left(a-b m_{i}-b r t\right)^{2} d r+\int_{R_{b}}^{R_{M}}\left[a-b m_{j}-b(S-r) t\right]^{2} d r\right\}
\end{aligned}
$$

The first two integrals collect consumer surplus on both sides of the incumbent's market. The third integral sums up surplus within the part of the formerly monopolistic market that is now served by the newcomer. We obtain the following proposition: 


\section{Proposition 2}

There is always a distance $S^{*}$, with $S^{\prime}<S^{*}<S^{\prime \prime}$ between the firms' sites, above which total consumer surplus decreases due to market entry.

$$
\Psi_{C}<\Psi_{M} \forall S \in\left(S^{*}, 2 R_{M}\right)
$$

The proof of this proposition goes as follows: If a newcomer enters at distance $2 R_{M}$ from the incumbent's site, consumers' surplus within the incumbent firm's market area is not affected, since the firm remains a local monopoly. To check whether consumers may be better off with a monopoly, it suffices to calculate the derivative of (14) with respect to $S$ at point $S=2 R_{M}$. If the derivative is positive, consumer surplus must have been lower than with monopoly for some $S<2 R_{M}$. The total derivative of (14) with respect to $S$ is

$$
\frac{d \Psi_{C}}{d S}=\frac{\partial \Psi}{\partial S}+\frac{\partial \Psi}{\partial m_{i}} \cdot \frac{\partial m_{i}}{\partial S}
$$

Since $\partial \Psi / \partial m_{i}<0$ and $\partial m_{i} / \partial S<0, \forall S>S^{\prime}$ (proposition 1), the second term is unambiguously positive at $S=2 R_{M}$. To prove that the total derivative is positive, it suffices to show that $\partial \Psi / \partial S$ is nonnegative. This derivative is

$$
\frac{\partial \Psi}{\partial S}=\frac{1}{2}\left(a-b m-b t \frac{S}{2}\right)^{2}-\frac{7}{8} b^{2} t^{2}\left(S-2 R_{M}\right)^{2}
$$

At $S=2 R_{M}$ the value is zero, thus the total derivative (16) is positive.

\section{Conclusions}

In this note we show that the mill price of the incumbent firm unambiguously rises due to market entry, if the site of the newcomer is outside of the former monopolist's market. This result, which contradicts the presumption that competition decreases prices, generalizes the findings of Perloff et al. (1996). If the monopolist faces a fixed market boundary at the other side, even entry within the former monopolist's market may lead to price rises. Moreover, total consumer surplus may fall due to market entry despite the induced reduction in transport costs.

Important limitations arise through the assumptions of linear individual demand functions and symmetric firms. The results do not carry over without alteration if e.g. isoelastic demand functions are considered. Since linear demand functions are most common in this field (and not less realistic than any other type), we think that 
our point is nonetheless worth being made. Without symmetry, the model would lose tractability, but the qualitative results would persist. Consider for instance the case where the newcomer fetches a higher price than the incumbent. Then the incumbent loses a smaller share of the market. The point where the positive effect on the incumbent's price (lower average elasticity of demand) and the negative (loss of market share) match each other would be reached later, i.e. more closely to the incumbent's site.

\section{References}

Beckmann, M. J. (1968) Location Theory Random House, New York.

Perloff, J. M., V. Y. Suslow, and P. J. Seguin (1996) "Higher Prices from Entry: Pricing of Brand-Name Drugs" Working Paper Series 11026 Department of Agricultural \& Resource Economics, University of California at Berkeley.

Puu, T. (2001) "Bertrand Oligopoly Revisited" Discrete Dynamics in Nature and Society $6,1-10$. 